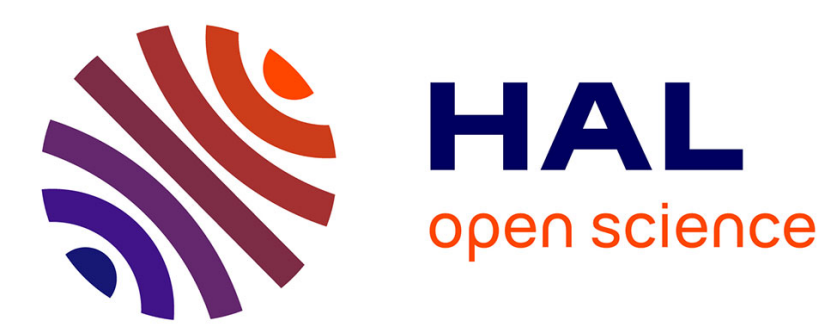

\title{
A new algorithm for image processing based on the properties of neural nets
}

J. Hérault, G. Bouvier, A. Chehikian

\section{To cite this version:}

J. Hérault, G. Bouvier, A. Chehikian. A new algorithm for image processing based on the properties of neural nets. Journal de Physique Lettres, 1980, 41 (3), pp.75-77. 10.1051/jphyslet:0198000410307500 . jpa-00231725

\section{HAL Id: jpa-00231725 https://hal.science/jpa-00231725}

Submitted on 1 Jan 1980

HAL is a multi-disciplinary open access archive for the deposit and dissemination of scientific research documents, whether they are published or not. The documents may come from teaching and research institutions in France or abroad, or from public or private research centers.
L'archive ouverte pluridisciplinaire HAL, est destinée au dépôt et à la diffusion de documents scientifiques de niveau recherche, publiés ou non, émanant des établissements d'enseignement et de recherche français ou étrangers, des laboratoires publics ou privés. 


\title{
A new algorithm for image processing based on the properties of neural nets
}

\author{
J. Hérault, G. Bouvier and A. Chehikian \\ Laboratoire du Signal Bioélectrique et de la Reconnaissance des Formes I.N.P. Grenoble. \\ ENSER, 23, rue des Martyrs, 38031 Grenoble Cedex, France
}

(Résu le 22 janvier 1979, révisé le 12 novembre, accepté le 10 décembre 1979)

\begin{abstract}
Résumé. - En partant des propriétés d'une structure de réseau nerveux à inhibitions latérales récurrentes, on définit un nouvel algorithme de traitement non linéaire d'images. Par le choix convenable des paramètres du réseau, on obtient, après un premier effet de lissage, soit une amélioration de contraste, soit un échantillonnage spatial s'adaptant aux singularités de la forme traitée.
\end{abstract}

Abstract. - Starting from the properties of a neural network with backward lateral inhibitions, we define a new algorithm suitable for non-linear image processing. From a convenient choice of the network parameters we obtain, after an initial smoothing effect, either a sharpening effect, or a spatial sampling adapted to the singularities of the input pattern.

Structures with so called backward lateral inhibitions, are present in the whole circuitry of the central nervous system, specially in the cerebral cortex [1]. As physiologists have observed in their behaviour the existence of contrast enhancement functions, we have been interested in studying these structures by means of mathematical models, in order to investigate their information processing properties. We have pointed out not only a contrast enhancement function but also a spatial sampling effect $[2,3]$, following an initial smoothing effect [10].

We present here some applications of these properties in image preprocessing suitable for optical reading $[4,5]$.

1. Neuron model and lateral inhibition network. THE NEURON. - A very simple analog of the neural function is that which represents the nervous information by the frequency of spikes, i.e. a continuously varying signal.

In this model, the neuron is a non-linear device with excitating $\mathrm{e}_{i}^{+}$and inhibiting $\mathrm{e}_{k}^{-}$inputs (dendrites), generating output spikes (on the axone) at a frequency $S$ :

$$
S=A\left(\sum_{i} \alpha_{i} \mathrm{e}_{i}^{+}-\sum_{k} \beta_{k} \mathrm{e}_{k}^{-}-\varepsilon\right)
$$

with the following restrictions :

$S=0$ if the right hand part is negative or zero.

$S=S_{\text {at }}$ if the right hand part is greater than or equal to $S_{\text {at }}$ (Saturation frequency of spikes).
In equation (1), $\alpha_{i}$ and $\beta_{k}$ are positive weighting coefficients, $A$ is the gain in the linear region, $\varepsilon$ the threshold.

THE BIDIMENSIONAL NETWORK WITH BACKWARD LATERAL INHIBITIONS. - In such a net, neurons, in the manner of pyramidal cells of cerebral cortex, are connected according to the scheme of figure 1 . One can see :

- an input plane for the excitation function $E(m, n)$,

- a processing plane $\sigma(m, n)$,

- an output plane for the output signal $S(m, n)$.

Simulating the network by digital computing, we represent the input and output plane by

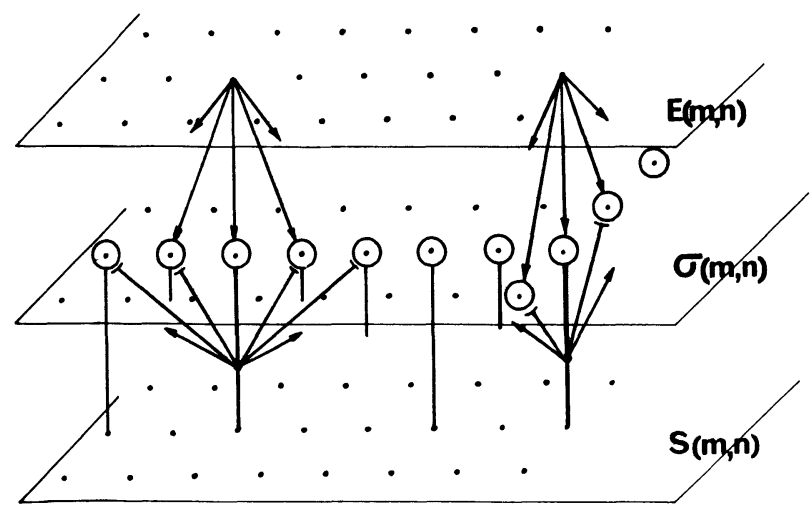

Fig. 1. - Schematic representation of a nerve net with lateral inhibitions. Each circle represents the neural operator. $\rightarrow$ excitating inputs, $\longrightarrow$ inhibiting inputs. 
$32 \times 32$ matrices, and the processing plane by the resolution of a system of 1024 equations such as :

$$
\begin{array}{r}
S(m, n)=A\left(\sum_{i=-a}^{+a} \sum_{j=-a^{\prime}}^{+a^{\prime}} \alpha(i, j) E(m-i, n-j)-\right. \\
\left.-\sum_{k=-b}^{+b} \sum_{l=-b^{\prime}}^{+b^{\prime}} \beta(k, l) S(m-k, n-l)-\varepsilon\right)
\end{array}
$$

with the following restrictions :

$$
S(m, n) \in\left[0, S_{\mathrm{at}}\right]
$$

for $m, n \in[0,31]$.

In equation (2), $\left(a, a^{\prime}\right)$ and $\left(b, b^{\prime}\right)$ are the boundaries of definition of the positive weighting coefficients $\alpha(i, j)$ and $\beta(k, l)$.

Because of the non-linearity of the neural function, this structure although identical to those of digital recursive filters, cannot be dealt by the usual methods $[8,9]$.

The derived image processing algorithm exhibits peculiar properties which we now describe.

2. Image processing applications. - Equation (2) describes two fundamental effects which are as well known in neurophysiology as in signal processing $[6,7,8]$.

1) A smoothing effect, due to the sum of the terms $\alpha(i, j) E(m-i, n-j)$ which defines a spatial low-pass filter.

2) A sharpening effect, due to the feedback operating sum of $\beta(k, l) S(m-k, n-l)$ which defines a spatial high pass filter.

By acting on the gain $A$ of the neurons, it is possible either to control the sharpening effect, or bring the system towards instability. In this case, the neuron's non linearities shortcut the output amplitude.

The distribution of maximums of outputs $S(m, n)$ is fitted on the discontinuities of the input pattern in accordance with the periodicity induced by the lateral inhibitions. The result is a sort of spatial sampling of the input pattern, always fitted on its singularities ; the sampling rate, first defined by the structure of the net adjusts itself to the dimension of the input pattern.

We illustrate these properties for two examples :

- Figure 2 displays the response of the net to an input $E(m, n) \equiv 1 \forall m, n \in[5,25]$. Outputs $S_{1}, S_{2}, S_{3}$ corresponding to gain $A=5,10,30$, show the behaviour of a net in which the domain of lateral inhibitions exceeds that of the excitation. For low gain, the sharpening effect dominates the other effects; for high gains the sampling effect appears.

- Figure 3 illustrates a concrete application of this algorithm to pattern functions of alphanumeric characters. We expressly chose characters « 2 » and « $Z$ », frequently mistaken in pattern recognition devices (Fig. 3a).
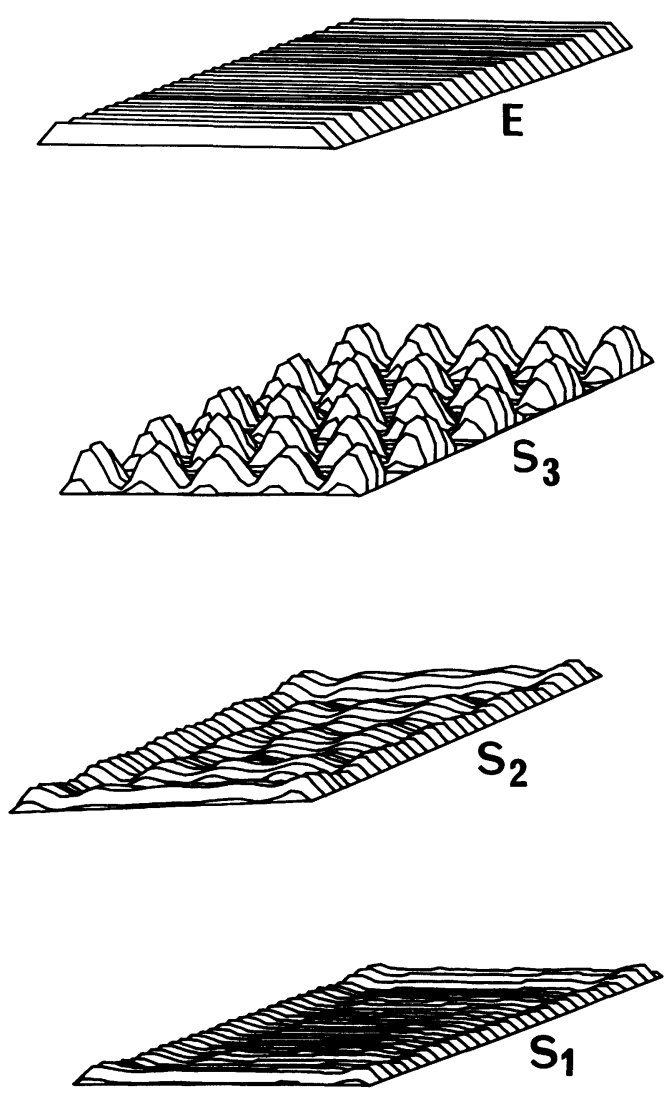

Fig. 2. - Behaviour of a net with lateral inhibitions in presence of a uniform valued input. $E$ : input pattern, $S_{1}$ : output function with $A=5, S_{2}$ : with $A=10, S_{3}$ : with $A=30$.

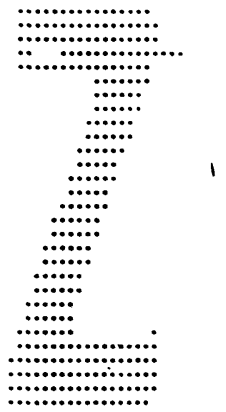

a

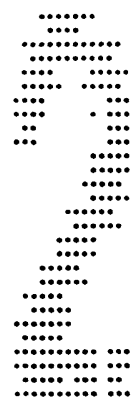

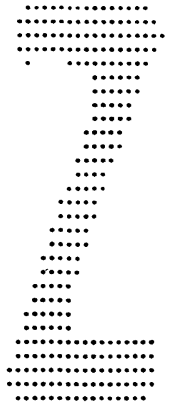

b

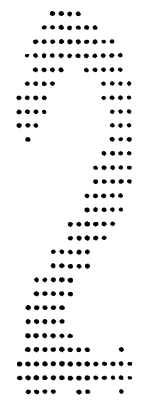

Fig. 3. - Application to processing of alphanumeric characters, a) input pattern, $b$ ) result with $A=1$ (smoothing), $c$ ) result with $A=30$ (spatial sampling). 
Responses are quantized on two levels in order to facilitate their display.

Figure $3 b(A=1)$ shows the smoothing effect, isolated points are cancelled, voids are filled. Here, the sharpening effect is not observable because of the two level quantization.

Figure $3 c(A=30)$ shows the sampling effect. After this processing, alphanumeric characters are depicted by a low number of clustered points, without any loss of structural information due to the fact that the clusters are always centred on characteristic regions of the pattern (line ends, changes of direction...). The redundancy is noticeably reduced.
3. Conclusion. - Unlike classical processes in which, smoothing, sharpening and sampling functions [9] are realized with specific operators, our method allows the choice between these functions or combinations of them, by means of only one control parameter of a single algorithm. As for the cortical nervous structure, this method operates a recursive and non linear processing. Moreover, the sampling effect is a specific property of this algorithm and when applied to images, whose meaning lies in the structural content (such as alphanumeric characters), it provides a description by a minimum set of samples preserving the useful information for recognition.

\section{References}

[1] BuSER, P., Imbert, M., Neurophysiologie fonctionnelle (Herman), Paris 1975

[2] Duval, F., Modélisation de structures nerveuses à inhibitions latérales et longitudinales. Thèse de Docteur-Ingénieur, Institut National Polytechnique de Grenoble (1974).

[3] Duval, F., Hérault, J., Filtrage spatial dans les réseaux nerveux, C.R. Hebd. Séan. Acad. Sci. Paris, 286D (1978) 217.

[4] Chehikian, A., Bouvier, G., Appareil d'acquisition de texte pour machine à reconnaissance de formes. Brevet ANVAR $\mathrm{n}^{\circ} 73.46 .285$ (1973)

[5] Chehikian, A., Bouvier, G. Un procédé de reconnaissance structurelle des caractères alphanumériques. Congrès AFCET-IRIA, Reconnaissance des Formes, pp. 303309, IRIA Ed. Paris (1978)
[6] KiRsChFELD, K., REICHADT, W., Die Verarbeitung stationärer optischer Nachrichten in Komplexauge von Limulus. Kybernetik, 2,2, 43 (1964).

[7] Hartline, H. K., RatlifF, F., Studies on Excitation and inhibition in the retina. (Chapman and Hall), London 1974.

[8] Messereau, R. M., Duddgeon, D. E., Two Dimensional Digital Filtering Proc. IEEE 63 (1975) 610-623.

[9] Pratt, W. K., Digital image processing (Wiley-Interscience) New York 1978.

[10] Hérault, J., Bouvier, G., Le traitement d'images par un modèle de réseau nerveux. 2" Congrès AFCET-IRIA, Rec. des Formes et Intelligence Artificielle, Tome III, pp. 72-77, IRIA, Ed. Paris (1979). 